\title{
Patient Representation and Advocacy for Alzheimer Disease in Germany and Israel
}

\author{
Silke Schicktanz • Nitzan Rimon-Zarfaty • Aviad Raz • \\ Karin Jongsma
}

Received: 31 July 2017 / Accepted: 15 April 2018 /Published online: 31 July 2018

(C) The Author(s) 2018

\begin{abstract}
This paper analyses self-declared aims and representation of dementia patient organizations and advocacy groups (POs) in relation to two recent upheavals: the critique of social stigmatization and biomedical research focusing on prediction. Based on twenty-six semi-structured interviews conducted in 2016-2017 with members, service recipients, and board representatives of POs in Germany and Israel, a comparative analysis was conducted, based on a grounded theory approach, to detect emerging topics within and across the POs and across national contexts. We identified a heterogeneous landscape, with the only Israeli PO focusing strongly on caretakers, whereas in Germany several POs claim to represent this patient collective.
\end{abstract}

S. Schicktanz $(\bowtie) \cdot$ N. Rimon-Zarfaty $\cdot$ K. Jongsma Department for Medical Ethics and History of Medicine, University Medical Center Göttingen, Humboldtallee 36, 37073 Goettingen, Germany

e-mail: sschick@gwdg.de

N. Rimon-Zarfaty

e-mail: Nitzan.Rimon-Zarfaty@medizin.uni-goettingen.de

K. Jongsma

e-mail: Karin.Jongsma@medizin.uni-goettingen.de

N. Rimon-Zarfaty · A. Raz

Department of Sociology and Anthropology, Ben-Gurion

University of The Negev, Beer Sheva, Israel

A. $\operatorname{Raz}$

e-mail: aviadraz@bgu.ac.il
Shared aims of all POs were fighting social stigma, balancing the loss of patients' individual autonomy, and the well-being of caretakers. By highlighting the emergence of new groups of dementia self-advocacy against the more traditional advocacy by others, this study highlights how advocacy and representation in the context of $\mathrm{AD}$ are embedded in the discursive context of stigmatization and revised disease conception. Future developments in early diagnosis and prediction of dementia, with more affected people likely to conduct dementia self-advocacy, might challenge existing representation structures even more.

Keywords Patient organization - Advocacy - Dementia . Representation $\cdot$ Stigma $\cdot$ Disease conception

\section{Introduction}

In the last decades, various organizations, associations, and support groups have emerged around chronic patients and people with disabilities as well as their families, mobilizing their "lay expertise" (Epstein 1998) for mutual support, improved health services and access, advocacy, and collaborative research. This article continues and extends previous analyses on such "patient organizations" (POs) by analysing POs for and of dementia in Germany and Israel. For practical reasons, we use the term "patient organization" as an umbrella concept to encompass a variety of patients/disability advocacy organizations aimed at advocating and promoting 
the rights and interests of patients/people with disabilities and their family members/caretakers. Organizations for such disabilities were established by caretakers or professionals, and organizations of were established by and comprised of people with disabilities themselves. This distinction between of and for is our own conceptualization of a development that has been recognized by others (see, e.g., Gilmour and Brannelly 2010; Moreira et al. 2014).

While previous research on the dynamics of POs and disability advocacy organizations focused on POs involvement in healthcare and research settings (Rabeharisoa et al. 2014; Luce et al. 2011) or on their emancipatory activities (Epstein 1998), we wish to examine these POs as (sometimes conflicting) assemblages of caretakers and patients/people with disabilities in order to gain insights into POs' claims for empowering collective representation, advocacy, and autonomy. These claims are becoming an important expression of deliberative democracy (e.g., Elster 1998) in the context of neo-liberal managed care and health governance (Dent 2006).

These developments highlight the complex and littleunderstood issues involved in collective representation in the context of health activism: Does patient advocacy always equal self-advocacy? Should this self-advocacy be prioritized over other forms of advocacy for the patient's best interest by parents, relatives, caretakers, or doctors? These questions loom large in the context of frailty, vulnerability, and social participation, and continue to present ethical, social, and political challenges for an inclusive society (for a detailed analysis of representative styles in autism POs, see also Raz et al. 2018).

In particular, we scrutinize how the political role and self-understanding of POs are interlinked with the current debate of medical conceptions of Alzheimer's disease (AD). Dementia advocacy often entails a focus on AD but usually also address other types of dementia. Hence, Alzheimer remains a label in many large POs' names in Germany and Israel due to historical reasons. Besides, the media refers rarely to other types of dementia (e.g. frontotemporal or vascular dementia). Dementia, and in particular $\mathrm{AD}$, advocacy offers an interesting topic for investigating the complex interplay of political representation and disease conception for several reasons.

First, AD is an important area where issues of representation and advocacy are pertinent (Golander and Raz 2000). While traditional advocacy for $A D$ is dominated by caretaker relatives, other associations for $\mathrm{AD}$ publicly identify themselves as caretakers' and patients' organizations, reflecting a process of hybridization (O’Donovan et al. 2013). Second, the current debate around $\mathrm{AD}$ is characterized by two important upheavals: On the one hand, critical voices impeach the medicalization, stigmatization, and social exclusion related to AD (Werner et al. 2012; Lock 2013; Hazan 2014). On the other hand, biomedical research on the early stages of dementia currently revises the main assumption about the aetiology and trajectory of AD. Alzheimer's disease is now understood as a continuum and as a slowly progressing syndrome with a long preclinical phase. It is assumed that it starts with an asymptomatic stage and develops into a symptomatic stage involving 'subjective' or 'mild' cognitive impairment (SCI/ MCI). Eventually it converts into a clinical syndromal disease with an already advanced pathology (Le Couteur et al. 2013; Dubois et al. 2016). Both upheavals impact the scenery of self-advocacy. Alzheimer's disease advocacy has been dominated by caretakers of AD patients (POs for), because patients have been deemed incapable of self-advocacy and self-care. Now, "patients" in the early and even preclinical stages of the disease are increasingly involved in health activism (POs of) (Beard 2004).

Furthermore, we employed a national-comparative approach that allows us to reflect upon the impact of the sociocultural framework on this mutual relationship between representation claims and disease conception. For building more general hypotheses, we consequently conducted interviews with representatives of the $\mathrm{AD}$ POs' board and with PO members in Germany and Israel, which are two Western, industrialized countries with social healthcare systems.

Comparing Germany and Israel in the Context of Alzheimer's Disease Patient Organizations

Germany and Israel provide a proper basis for this analysis for several reasons. Both countries have issued declarations about the importance of the participation of POs in parliament committee hearings and governmental committee deliberations (Schicktanz and Jordan 2013; Shalev and Hashiloni-Dolev 2011). Furthermore, both countries are at the cutting edge of Western medical progress, with well-developed social healthcare systems. Israel developed a national dementia strategy in 2013, while the German Ministry of Health and Ministry for Social Affairs established an "Alliance for people with dementia" in 2012, which provides a platform to 
develop strategies and provides information about dementia care. Yet Germany and Israel often represent opposing bioethical regulations and policy processes, in which POs also play a role (Raz and Schicktanz 2016). For example, in end-of-life decisions, Germany is rather permissive in comparison to Israel. It allows passive euthanasia if patients wish it and requires doctors to follow advance directives quite strictly, independently of how and when they have been composed. In Israel, passive euthanasia is allowed under very strict conditions, and advance directives are strictly regulated regarding format and registration (Schicktanz et al. 2010). However, in beginning-of-life healthcare, such as prenatal genetic testing and reproductive medicine, Israel is very permissive in comparison to Germany (Raz and Schicktanz 2009).

In both countries, disability politics and activism are based on the expansion of welfare and special needs provisions while the social movement for equal rights and integration followed later (inspired by the U.S. disability debate). Additionally, in both Germany and Israel, there is a (quite similar) Disability Act; but while in Germany the disability movement appears to have formed a mature coalition (Heyer 2002), in Israel there is no such coalition and the disability community is divided between sectors (disabled veterans/workplace disability/general disability), advocacy and service organizations, and even between competing organizations for political activism of people with disabilities (Gilad and Rimmerman 2014; Mor 2009). Similar to other European countries, in the last five years dementia has gained more attention and public awareness than ever before in both Germany and Israel, giving the impression of a "dementia hype" (Swinnen and Schweda 2015).

\section{Research Questions and Main Objectives}

Starting from these general political-ethical issues we want to examine how advocacy and representation in the context of $A D$ are embedded in the discursive context of stigmatization and revised disease conception. The comparative empirical analysis aims at detecting cross-cultural variances in debates and more general discursive structures otherwise easily overseen in local studies. In our analysis, we subsequently present similarities and differences in how German and Israeli POs of and for $\mathrm{AD}$ patients describe their practical and political aims, as well as their practices and positions towards representation. Moreover, we embed these findings in the current debates on stigmatization and pre-clinical dementia diagnosis. Finally, we conclude with some general reflections on the question of how representation is relevant for addressing ethical issues of patient involvement and collective decision-making in healthcare.

\section{Methodology}

The first stage of this study consisted of background analysis of guidelines, policies, websites, and reports regarding the status and involvement of dementia POs in Germany (GE) and Israel (IL) (for an additional comparative analysis of Germany and the United States, see also Schicktanz 2017). In Israel only one large PO exists for people with AD. EMDA-the Alzheimer's Association of Israel-was established in 1988 by family members as a nationwide association. It consists of about five hundred official members and provides service to 30,000 to 40,000 Israeli AD patients and family members. These numbers are based on EMDA's board member assessment as reported in a personal interview. Another non-profit, serviceoperating association is Melabev. This geriatric specialists' association focuses on care and service provision and less on advocacy and was therefore not included in our analysis. In Germany we identified various associations. The German Alzheimer Association is the largest umbrella organization for AD patients, consisting of about 15,000 official members in about 500 regional support groups. In addition, several small associations exist. Based on the background analysis, in each country we approached the politically most active and relevant POs. Each PO established a board consisting of one director (or so-called chairs) and various office holders. This board is usually responsible for decision-making and communication. Directors of these POs were contacted directly via email. Additional chairs and other board members were recruited using snowball-sampling via the directors. Professional contact from former academic workshops existed in two cases, but no personal contact between researchers and the interviewed representatives existed before. We approached additional smaller associations for and of AD patients on the basis of their public outreach and included therefore Alzheimer Ethics and Dementia Support Stuttgart (POs of), as well as a regional office of the umbrella organization and Action Dementia (POs for) into our sample (see table 1). In German POs of, people with dementia are directly involved in establishing or 


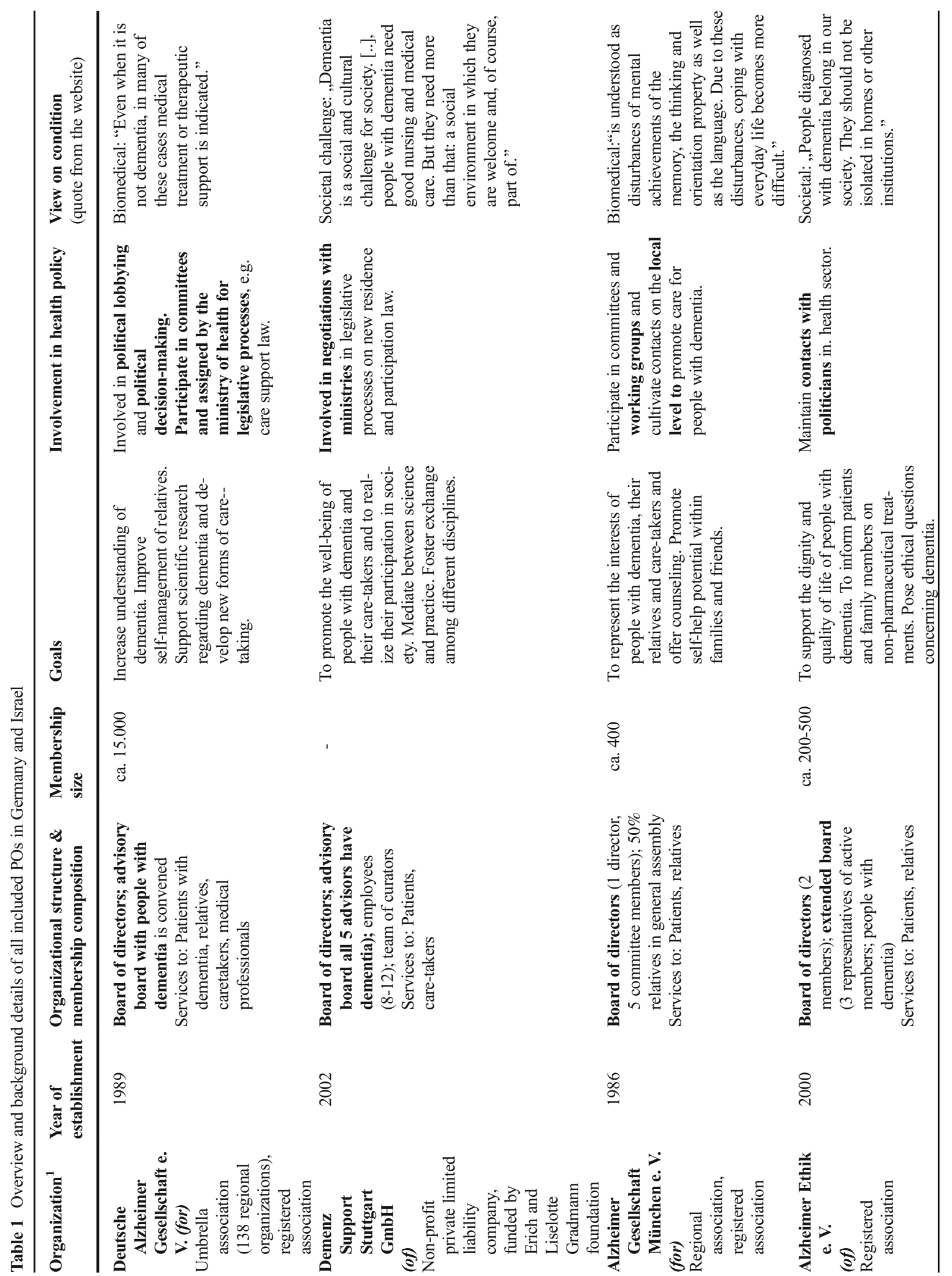




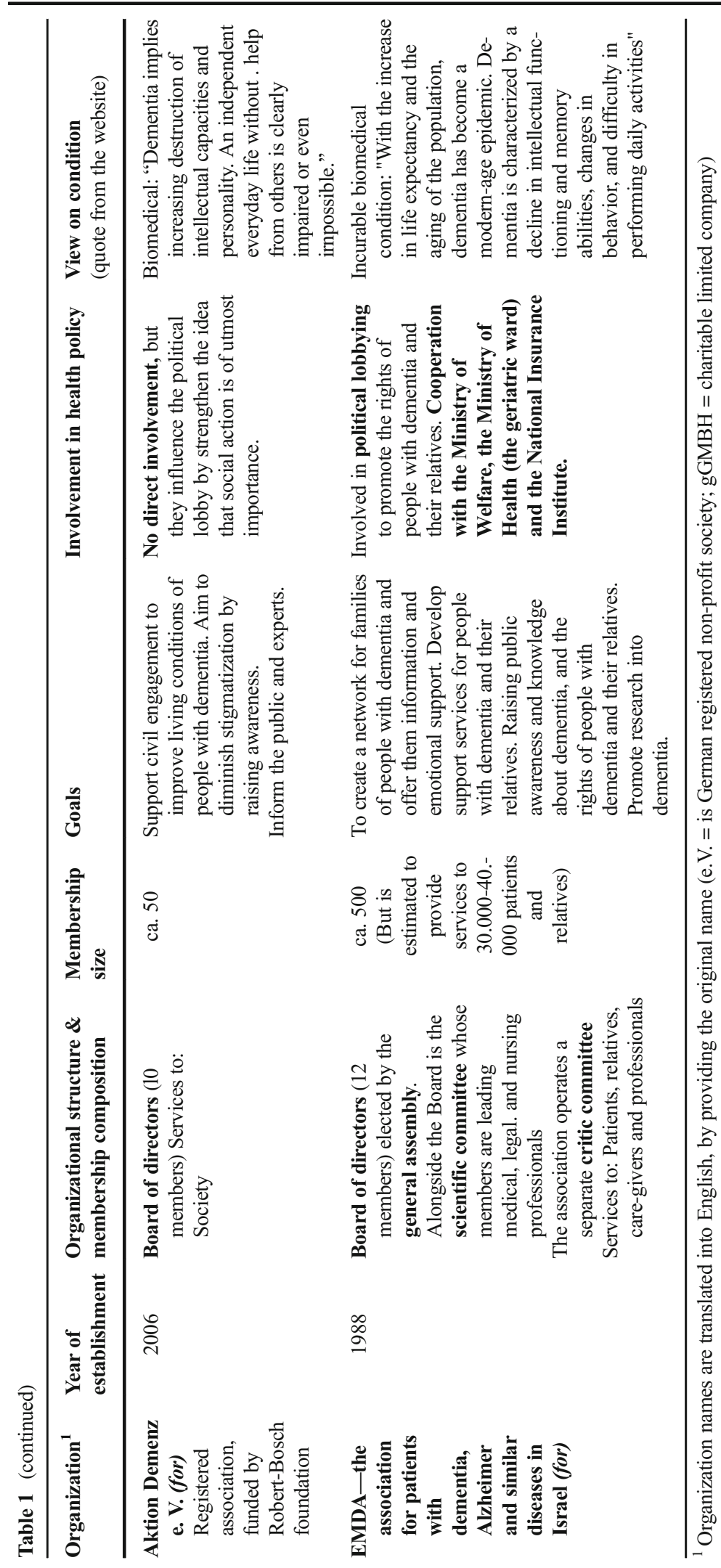


operating self-representation and advocacy. Overall, in 2016-2017 we conducted fourteen interviews in Germany and twelve in Israel. Overall, we interviewed three directors, two chairpersons, five board members, three other office holders, three members with $\mathrm{AD}$, and ten caretakers members/service recipients. Ten of participants were male and sixteen were female (see table 2). The interview collection was finalized when the research teams agreed that thematic saturation was reached, meaning that no new topics were raised in the subsequent interviews. In Germany, this took two more interviews. Research ethics approval was received from the Research Ethics Committees of Ben-Gurion University (Israel) and of University Medical Center Göttingen (Germany).

All interviews were semi-structured with similar questions asked in Germany and Israel (see the questionnaire for board members/office holders and regular members/service recipients in the supplementary material). Office holders were asked about the history of the organization, their activities, and the organizational goals, successes, and failures, relation to other associations, positions towards biomedical research, and the internal structures of decision-making, including the association's policies regarding the adequate representation of the range of voices present within its constituency. Association members were asked about their involvement in PO activities, to what extent they are involved in PO decision-making, how satisfied they are with it, and who should be involved in organizational decision-making. They were also asked about their position and activities towards care in dementia and towards ethical-legal debates. Interviewees were also asked about their personal link to AD advocacy (e.g., whether they were caretakers or diagnosed with dementia). Both were considered as phenomenologically "being affected" and also addressed in these terms in our interviews, in contrast to professional office holders who have had no personal involvement (non-affected). Interviews were conducted in the office or home of the respondents or over the telephone (when preferred by the interviewee) and lasted between thirty and ninety minutes. Association members/service recipients were recruited via office holders, the associations' website, and the associations' support groups; we used the snowball method to reach additional members. Consent was obtained from all participants. Interviews were digitally recorded and verbally transcribed. Transcripts were translated into English and anonymized, with the POs' names replaced by a code, PO1 to PO5. Using a grounded theory approach to data analysis (Corbin and Strauss 1990), emergent themes concerning perceptions and self-declared aims of the PO were identified through inductive coding using ATLAS.ti@. Interviews were first analysed thematically in each country and compared cross-nationally by the research team to uncover discursive themes connecting general representation styles found in the literature on disability advocacy with

Table 2 Overview of interviewees with POs in Germany and Israel

\begin{tabular}{|c|c|c|c|c|}
\hline Patient Organization & $\begin{array}{l}\text { board members and office } \\
\text { holders }\end{array}$ & $\begin{array}{l}\text { Member, with } \\
\text { AD }\end{array}$ & $\begin{array}{l}\text { member, family } \\
\text { caretaker }\end{array}$ & $\begin{array}{l}\text { Total } \\
\mathrm{N}\end{array}$ \\
\hline Germany & & & & 14 \\
\hline $\begin{array}{l}\text { German Alzheimer Association } \\
\text { (Deutsche Alzheimer Gesellschaft e. V.) }\end{array}$ & 1 & & 1 & 2 \\
\hline $\begin{array}{l}\text { Alzheimer Ethics } \\
\text { (Alzheimer Ethik e. V.) }\end{array}$ & 1 & 1 & 3 & 5 \\
\hline $\begin{array}{l}\text { Dementia Support Stuttgart } \\
\text { (Demenz Support Stuttgart gGmbH) }\end{array}$ & 1 & 1 & & 2 \\
\hline $\begin{array}{l}\text { Alzheimer Association Munich } \\
\text { (Alzheimer Gesellschaft München e. V.) }\end{array}$ & 1 & 1 & 1 & 3 \\
\hline $\begin{array}{l}\text { Action Dementia } \\
\text { (Aktion Demenz e. V.) }\end{array}$ & 1 & & 1 & 2 \\
\hline Israel & & & & 12 \\
\hline $\begin{array}{l}\text { EMDA- the Alzheimer's Association of Israel } \\
\text { בישראל דומות ומחלות אלצהיימר דמנציה לחולי עמדא) (עמותת }\end{array}$ & 8 & & 4 & 12 \\
\hline
\end{tabular}


the particular context of $\mathrm{AD}$, looking for themes and their variations recurring within and across organization type and country (Denzin and Lincoln 1994).

\section{Results}

Our analysis revealed the following three common topics. These are broadly shared and uncontroversial for Alzheimer advocacy in both countries: fighting social stigma, balancing the loss of individual autonomy, and the well-being of family caretaker (see table 3).

\section{Fighting Social Stigma}

Overall, our interviewees in both countries stressed that according to their perception, dementia is a "special" illness, highly associated with social stigmatization because of the progressive and irreversible influence on cognition that affects the personality of the person with dementia. Interviewees highlighted the differences between $\mathrm{AD}$ and other (now) less stigmatized illnesses such as cancer. This point was brought up by several interviewees.

The only explanation I have is that there is no cure for this disease. It is impossible to beat the disease. This disease usually does not harm children or young people. It is not a disease such as cancer, with heroic cases, that you can win it over and be a hero. So apart from suffering and shame, it is not accompanied by anything. And the public is not making his [the patient] voice heard. They are becoming more and more introverted and try to survive. (PO for, board member, Israel)

Overall, fighting stigma was perceived as a main goal for all the POs we studied, as demonstrated by the following quote of an interviewee with $\mathrm{AD}$ :

I do not want to be pathologized-I want to be seen as a human being and I want to be asked

Table 3 Overview of topics that emerged from the interviews with POs board members and constituency members in GE and IL

\begin{tabular}{|c|c|c|}
\hline & German POs & Israeli PO \\
\hline of/for: Shared topics & \multicolumn{2}{|c|}{$\begin{array}{l}\text { - Fighting social stigma: } \\
\text { Social acceptance as human being/citizen; treatment to improve conditions } \\
\text { - Balancing the loss of individual autonomy: } \\
\text { Collective voice for claiming individual needs in social and medical care; heteronomy } \\
\text { as normality; fighting for legal opportunities to extend autonomy (supported } \\
\text { decision-making as alternative to traditional guardianship, advanced directives) } \\
\text { - The well-being of family caretakers: }\end{array}$} \\
\hline For & \multicolumn{2}{|c|}{$\begin{array}{l}\text { In need of care themselves; but risk of overlooking the patient } \\
\text { - Biomedical model of dementia } \\
\text { - Public awareness of dementia: } \\
\text { Holistic approach in social/medical care (favouring dementia friendly community approaches) } \\
\text { - Representative political practice: } \\
\text { Trustee model (competence more important than having the disease) } \\
\text { - Intra-family relationships: } \\
\text { Family members idealized as trustees/no alternative }\end{array}$} \\
\hline For & $\begin{array}{l}\text { - Representation style: } \\
\text { More open to self-advocacy, but prefer a complementary approach }\end{array}$ & $\begin{array}{l}\text { Representation style: } \\
\text { Very critical towards self-advocacy, } \\
\text { insisting on caretakers or volunteers }\end{array}$ \\
\hline$o f$ & $\begin{array}{l}\text { - Public awareness of dementia: } \\
\text { Stressing agency and independency } \\
\text { of patients (favoring assistive } \\
\text { technologies) } \\
\text { - Representation style: } \\
\text { Ideal of self-representation/delegate } \\
\text { model } \\
\text { - Intra-family relationships: } \\
\text { Mentioning conflicting interests } \\
\text { between patients and care takers }\end{array}$ & N/A \\
\hline
\end{tabular}


accordingly. In the consultation, I expect to be treated a certain way, that means the language they use when talking to me. It should not be a language, for example, that goes as follows: "you are suffering, you poor, your mind is dwindling every hour, this deprivation, this perplexity. How do you fight these symptoms?" This is a language that shows me that they pathologize me and- they do not provide support, they take all away from us." (PO2 of, member with dementia, Germany)

The problem of social stigma led some office holders to mention their struggle to recruit new members, because being associated with the PO may exacerbate the member's stigma.

Overall, both POs, of and for, supported the biomedical model of dementia. Many POs provided a platform for recruiting potential research participants. The hope was that with better treatment and care, stigma and social exclusion will diminish. Therefore, involvement in, and collaboration with, scientific research, including biomedical research, was regarded positively, even though the POs' own direct financial investments in biomedical research were limited. In the case of the German Alzheimer Association, their funding of research was related to improving care, housing, or communication. In Israel, EMDA did not directly support or fund any kind of research but provided links to existing research for participation. However, many interviewees criticized the national policy for focusing too much on medical and hospital treatment and for setting very limiting criteria for social security support, and thereby overlooking the needs for specialized social support for caretakers as well as for persons with dementia outside the hospital context.

\section{Autonomy and the Caretaker}

Another theme shared by all interviewed PO members was the effect of the diagnosis of dementia on the autonomy of the diagnosed person. First, a diagnosis may lead to heteronomy, that is, being governed by third parties (e.g. family members gain the power to decide in minor and major life decisions, including decisions over driving, mobility, housing, and financial issues). A typical comment was:

[people with dementia] experience this as something very bad when they say: "As soon as I have this dementia ... in the sense of the diagnosis ... my relatives do not take me seriously anymore, suddenly decide all things, therefore terribly restricting my freedom.” This must be clarified from the beginning that too much of this approach under the notion of care- "It's me who decides now, I do not believe you are able anymore"-it is very, very discriminating for the person affected, I believe, that this makes him more incapacitated ... (PO3 of, board member, Germany)

Secondly, since $\mathrm{AD}$ is understood as a progressive neurodegenerative disease that will result in loss of memory, planning, orientation, and assessment, it makes the interpretation of the patient's wishes more challenging:

Sometimes the words of a person with dementia come from the dementia and not from himself. (PO for, member, caretaker and service recipient, Israel)

POs try to balance this loss of individual autonomy in several ways. According to their understanding, the collective voice replaces the individual voice in expressing needs and interests about care and treatments. Additionally, the POs engage in political debates in each country about advanced care directives or guardianship. This engagement can also be interpreted as "extension" of the autonomous individual voice (especially against the paternalism of professionals) to ensure (more) self-determination of the person with dementia. However, there remains an ambiguity in this position, as the POs for strongly favour the family caretaker as the best proxy for decision-making.

Alzheimer's disease was framed as a fatal disease characterized by loss of accountability and therefore mainly associated with obvious, already developed symptoms. The few active members with dementia were characterized as fitting into the category of very early stage of dementia. The topical issue of predictive testing of prodromal dementia was not mentioned by the interviewees.

It was expressed as typical of the condition that both patients and their families (as caretakers) are phenomenologically "affected by" AD. In contrast to other chronic diseases such as cancer or HIV where family members are rarely mentioned as an affected group, for dementia this was different. Family members who act as caretakers are seen as almost similarly affected:

... although we always argue, dementia is actually a disease of the relatives because they suffer quite a lot. (PO1 for, relative and caretaker, member, Germany) We have activities aimed to give patients quality of life, but we are more directed to providing the 
tools to enable caregivers and help them survive the process. (PO for, board member, Israel)

This focus on the caretaker entails the risk that the diagnosed person herself is not given the necessary attention anymore or that the burden of, and concerns for, the family caretakers are overemphasized. Some German interviewees stressed therefore the need to organize separate activities for caretakers and for people with dementia.

\section{Understanding Dementia in POs $O f$ and For}

Alongside these topical overlaps, we also identified important nuances in themes and opinions between POs for - both in Israel and Germany-versus the German POs of (see table 2). These differences can also be classified along the three themes of 1) public awareness of dementia, 2) representative political practice, and 3) intra-family relationships.

Regarding public awareness of dementia, POs for and POs of differed in the detailed characterization of how dementia should be framed. Germany and Israel POs for stressed a rather "holistic" approach of medical and social support for all affected persons, including patients and their relatives as caretakers. They also called to fight the tabooing of the disease as such and to provide comprehensive information for lay people about the progressive course of the disease.

... to get the subject a bit out of the taboo zone. This is very important to me, the more you know about it, the less fear you need to have. I do not want to play the topic down, and it is certainly, when one has a diagnosis, primarily for the affected person and of course for the family members certainly incredibly devastating. But there is a life after that. (PO5 for, relative and caretaker, member, Germany)

The POs of aimed at - literally — moving into society to raise awareness, showing their autonomy and agency despite the condition, by exposing the public to people with early stage dementia. Members with early stage dementia initiated several projects raising public awareness about the existing social mechanisms of exclusion and the fight for normalization - especially for patients in the early phases of dementia. Such activities included visits to schools and public institutions.

One German interviewee of a PO for stressed that normalization needs to be embedded in a dementia- friendly community and to allow ambulant support as long as possible:

So the goal is to keep living independently as long as possible, so in his own living environment and it starts, for example, that a household assistance is necessary (...). And then one gradually builds up the supply structure with some sort of shifts so that the relatives are relieved hourly (...) to a certain point, when it is perhaps not good any more to live alone at home, but it is then simply important that you move into a facility. (PO4 for, board member, Germany)

In slight contrast, the POs of stressed particular assistive technology for ensuring independence. As the quote indicates, the idea that sooner or later a care home will be the logical end, is yet not so self-evident.

Very important topics are, for example, assistive technology. When I feel worse, how I can help myself, yes, how I can help myself remain to live at home independently. (PO2 of, member with dementia, Germany)

While we gained the impression that POs of do benefit practically from members and representatives being diagnosed early, neither them nor PO for expressed a clinical/medical interest in early detection of dementia via biomarkers or genetic testing.

The difference between national neuro-cultures and self-advocacy became most visible in the understanding and practice of representation. At one end of the spectrum was the Israeli PO for which was not ready to have self-advocacy at all:

It fits American political correctness, but elsewhere? Then I ask you - what are they useful for? What contribution do they have to make? What can they contribute? I do not have a concrete example of such a contribution. I'm sceptical about that. (PO for, board member - non-caretaker, Israel)

The German POs for were more positive about selfadvocacy (some included persons with dementia in their advisory board) but defended a mixed, complementary approach:

The good thing is that nowadays the people with a dementia diagnosis can be diagnosed very early 
(...) and if you talk to the people who are earlyaffected, who are also able to express themselves, then they clearly say, "we speak here with a loud voice, but we also speak for the people who may already not have strong words, who do not find the words anymore." (PO4 for, board member, Germany)

In contrast, POs of stressed an ideal of selfrepresentation:

... it was not a topic at all here in Germany until at least some years ago (...). It was observed with disbelief and not understood what we actually aimed for; how we come to believe that those who are affected by dementia can actually think or articulate themselves. (PO3 of, board member, Germany)

Interviewees from POs for did not ignore potential conflicts that arise when caretakers and relatives speak on behalf of the patient. However, they either stressed the incapacity of the patients or the burden of caretakers:

Their voice is always through the family, unless there is a direct connection between the volunteer [an unpaid helper trained by the PO, the authors] and the patient, which is also usually a surprise to the family, whether it's in terms of its capabilities, whether it's things that the family thinks that he stopped doing and suddenly they discover that with the volunteer he still does. Often the volunteer comes in, usually in the early stages of the disease, and the patient is still less expressing himself, but a family member is expressing his wishes for him! So there it is. So really our volunteers are our ambassadors in the field. (PO for, office holder 3, Israel)

In contrast, interviewees from POs of explicitly and critically reflected upon problems with family members that even led to intra-familial discrimination. For them, it was important that family members acknowledge the person with the resources they still have. Interviewees from POs for also pointed out the emphasis on expectations regarding the competences of the caretaker (as attentive, trustful, creative, etc.). Interviewees from POs for tended to focus only on social discrimination and located the problem in the psychological denial of persons with dementia to recognize their limitations. Importantly, from a cross-cultural perspective, and though holding different positions in the context of intra-familial relationships, both POs of and for in Germany shared a resource-oriented rather than deficitoriented approach.

\section{Discussion}

Our findings highlight how beyond the shared public and political goals of AD advocacy, Germany has a more diverse landscape of AD organizations including organizations of people with early-stage dementia, in contrast to a more uniform landscape in Israel. By highlighting the emergence of dementia self-advocacy against the more traditional backdrop of advocacy by others, this study highlights how advocacy and representation in the context of $\mathrm{AD}$ are embedded in the discursive context of stigmatization and revised disease conception. In the Israeli PO for, we found a strong focus on caretakers in a double sense: they are considered competent to represent the patients' best interest, and the service provided by the PO is aimed at reducing the burden of caretakers. Here, the leading idea is that helping the caretaker will eventually help the patient. Scepticism towards self-representation of people with dementia is based on the assumption that dementia is related to denial and loss of self-identity.

However, the lack of self-representation of people with AD might increase the social stigma as it fuels existing stereotypes of helplessness, identity loss, and incapacity (Beard 2004). In political-ethical terms, the issue of self-representation is less a question of efficacy of interest presentation than of political selfdetermination (Williams 1998). The misrecognition of the right of people with $\mathrm{AD}$ to represent themselves may be internalized by them and further harm their selfesteem and sense of agency, which may lead to the reinforcement of hierarchies impeding equal participation (Williams 2014).

In Germany we observed a larger pluralism regarding representative structures as they exist now in POs of and for. This plurality leads to a more explicit recognition of the inherent limits of representation-styles and has created a discursive space of critical but friendly interaction. However, one needs to be realistic that the wellestablished and politically better-integrated POs for leave only little room in the political landscape to be filled by upcoming POs of. In other areas, such as autism, a split of POs of and for results in POs of often 
questioning their status as patients by understanding themselves as "neurodiverse," but not as ill or pathologic (Raz et al. 2018; Chamak 2008). In the context of dementia POs, however, such radical split with regard to political aims and conceptualization of the condition is absent. One explanation may be found in the existing social stigmatization of dementia and insufficient healthcare structures for dementia care. These two social obstacles form a joint, unquestioned premise for both POs of and for and unify them in their advocacy aims. However, it can be argued that under such conditions of social stigma, which stress and amplify the loss of the patient's self-determination, agency, and autonomy, the new emergence of self-advocacy dementia groups is in itself radical. The rather passive, yet positive, attitude towards biomedical research of POs in Germany and Israel differs from the American Alzheimer Association, which is a leading player in biomedical and pharmaceutical research as well as in neuro-imaging and predictive testing of dementia, especially AD. The main focus of the POs in Germany and Israel is rather on fighting social stigma by improving social and community structures. The occurrence of dementia self-advocacy in Germany but not in Israel indicates the cultural entanglement of stigma and advocacy in the context of dementia. It even highlights a problematic ambiguity when POs for address the stigma of dementia especially as part of fundraising campaigns that capitalize on vulnerability, but by this, they may inadvertently amplify it. Many of the Israeli office-holders of the PO for stressed that stigma was the reason for the organizational agenda of raising awareness, as well as the explanation why earlystage dementia patients were not ready to pay the social price of being labelled as persons with dementia, thus avoiding the PO's services. It appears that POs of, such as those in Germany, have a crucial role to play in breaking this vicious circle of stigma of dementia.

Overall, a general ethical issue from a theoretical perspective remains as to how the patient perspective can be represented in a balanced and consistent way in healthcare politics: The possibility of self-advocacy warrants assistance and support, even if the relatively newer and smaller POs of dementia that are emerging in Germany have not yet differentiated themselves so much, in terms of what they are lobbying for, from the POs for. In comparison to Alzheimer Europe and Alzheimer US

\footnotetext{
$\overline{{ }^{1} \mathrm{http} / / / \mathrm{www} . a l z h}$ eimer-europe.org/Policy-in-Practice2/Our-opinionon/Advance-directives
}

and their focus on "expert" and professional voices, the integration of early diagnosed patients or highfunctioning patients in advocacy structures can be understood as convergence and might strengthen the existing PO for. For example, the umbrella organization Alzheimer Europe started to stress the positive potentials of early diagnosis for preparing advance care planning and advance research directives, ${ }^{1}$ but is very hesitant to discuss the concrete potential for its own practice of political representation. Future research on these debates and negotiations could help to identify the limits of scepticism or political interests and foster a critical discussion. In this sense, we speculate that current developments in dementia diagnostics and prediction will likely lead to more interesting changes in the structures of POs in case the POs are overall open for these developments.

\section{Limitations of the Study}

The small sample in our study (twelve interviews in Israel and fourteen interviews in Germany) limits the claim for generalization of our findings. The main aim of our study was to explore working hypotheses regarding the diverse aims and approaches of collective representation in Alzheimer POs, to describe and reflect on the normative implications of and cultural impacts on the division between POs of and for. Examining dementia POs in other countries would be helpful to understand how our observations are part of a larger crosscultural landscape in dementia advocacy.

Acknowledgements We like to thank Elisabeth Späth, Göttingen, Bosmat Bar-Nadav, Ben-Gurion and Ella Vaintropov, Ben-Gurion for practical support in data collection, editing and preparation for preliminary analysis. We like to thank all participants for their willingness to share time and their opinions with us. This study is funded by the State of LowerSaxony Hannover, Germany, grant11,762,519,917/14(ZN3010), which we gratefully acknowledge. The funding did not have any influence on the conduct, design, collection, analysis, and writing of this article.

Open Access This article is distributed under the terms of the Creative Commons Attribution 4.0 International License (http:// creativecommons.org/licenses/by/4.0/), which permits unrestricted use, distribution, and reproduction in any medium, provided you give appropriate credit to the original author(s) and the source, provide a link to the Creative Commons license, and indicate if changes were made. 


\section{References}

Beard, R.L. 2004. Advocating voice: Organisational, historical and social milieux of the Alzheimer's disease movement. Sociology of Health and Illness 26(6): 797-819.

Chamak, B. 2008. Autism and social movements: French parents' associations and international autistic individuals' organisations. Sociology of Health \& Illness 30(1): 76-96.

Corbin, J., and A. Strauss. 1990. Grounded theory research: Procedures, canons, and evaluative criteria. Qualitative Sociology 13(1): 1-21.

Dent, M. 2006. Patient choice and medicine in health care: Responsibilisation, governance and protoprofessionalisation. Public Management Review 8(3): 449462.

Denzin, N.K., and Y.S. Lincoln. 1994. Handbook of qualitative research. Thousand Oaks: Sage Publications.

Dubois, B., H. Hampel, H.H. Feldman, et al. 2016. Preclinical Alzheimer's disease: Definition, natural history, and diagnostic criteria. Alzheimers Dementia 12(3): 292-323.

Elster, J. 1998. Deliberative democracy. Cambridge: Cambridge University Press.

Epstein, S. 1998. Impure science: AIDS, activism, and the politics of knowledge. Berkeley: University of California Press.

Gilad, D., and A. Rimmerman. 2014. The mission and development processes of the disability movement in Israel and the United States: A comparison. Journal of Disability Policy Studies 24(4): 227-237.

Gilmour, J.A., and T. Brannelly. 2010. Representation of people with dementia - subaltern, person, citizen. Nursing Inquiry 17(3): 240-247.

Golander, H., and A.E. Raz. 2000. The mask of dementia: Images of 'demented residents' in a nursing ward. In Aging and everyday life, edited by J. Gubrium and J. Holstein, 357369. Oxford: Blackwell.

Hazan, H. 2014. Against hybridity. Social impasses in a globalizing world. Cambridge: Polity Press.

Heyer, K.C. 2002. The ADA on the road: Disability rights in Germany. Law \& Social Inquiry 27(2): 723-762.

Le Couteur, D.G., J. Doust, H. Creasey, and C. Brayne. 2013. Political drive to screen for pre-dementia: Not evidence based and ignores the harms of diagnosis. British Medical Journal (Online) 347(7925).

Lock, M. 2013. The Alzheimer conundrum: Entanglements of dementia and aging. Princeton: Princeton University Press.

Luce, J., L. Giorgi, K. Paul, et al. 2011. Health matters: A social science and ethnographic study of patient and professional involvement in the governance of converging technologies in medicine. HealthGovMatters project report. http://cordis. europa.eu/project/rcn/91215_en.html. Accessed June 20, 2018.

Mor, S. 2009. Disability rights in Israel: Between socio-political and legal recognition. In Access to justice and social rights, edited by J. Gal and M. Eisenstadt, 80-130. Jerusalem: Taub Center for Social Policy Studies in Israel.
Moreira, T., O. O’Donavan, and E. Howlett. 2014. Assembling dementia care: Patient organisations and social research. BioSocieties 9(2): 173-193.

O’Donovan, O., T. Moreira, and E. Howlett. 2013. Tracking transformations in health movement organisations: Alzheimer's disease organisations and their changing "cause regimes". Social Movement Studies 12(3): 316-334.

Rabeharisoa, V., T. Moreira, and M. Akrich. 2014. Evidence-based activism: Patients', users' and activists' groups in knowledge society. BioSocieties 9(2): 111-128.

Raz, A., K.R. Jongsma, N. Rimon-Zarfaty, E. Späth, B. BarNadav, E. Vaintropov, and S. Schicktanz. 2018. Representing autism: Challenges of collective representation in German and Israeli associations for and of autistic people. Social Science \& Medicine 200: 65-72.

Raz, A., and S. Schicktanz. 2016. Comparative empirical bioethics: Dilemmas of genetic testing and euthanasia in Israel and Germany. Heidelberg: Springer.

Raz, A., and S. Schicktanz. 2009. Diversity and uniformity in genetic responsibility: Moral attitudes of patients, relatives and lay people in Germany and Israel. Medicine, Health Care and Philosophy 12(4): 433-442.

Schicktanz, S. 2017: The visionary shaping of dementia research: Imaginations and scenarios. in biopolitical narratives and ethical reflections. In Planning later life-Bioethics and public health in ageing societies, edited by M. Schweda, L. Pfaller, K. Brauer, F. Adloff, and S. Schicktanz, 205-227. Abingdon: Routledge.

Schicktanz, S., and I. Jordan. 2013. Kollektive patientenautonomie. Theorie und praxis eines neuen bioethischen konzepts. In Patientenautonomie. Theoretische grundlagen-Praktische anwendungen, edited by C. Wiesemann and A. Simon, 287302. Münster: Mentis.

Schicktanz, S., A. Raz, and C. Shalev. 2010. The cultural context of end-of-life ethics: A comparison of Germany and Israel. Cambridge Quarterly of Healthcare Ethics 19(3): 381-394.

Shalev, C., and Y. Hashiloni-Dolev. 2011. Bioethics governance in Israel: An expert regime. Indian Journal of Medical Ethics 8(3): 157-160.

Swinnen, A., and M. Schweda, eds. 2015. Popularizing dementia. Public expressions and representations of forgetfulness. Bielefeld: Transcript.

Werner, P., S. Mittelman, D. Goldstein, and J. Heinik. 2012. Family stigma and caregiver burden in Alzheimer disease. Gerontologist 52(1): 89-97.

Williams, M. 1998. Voice, trust, and memory: Marginalized groups and the failings of liberal representation. Princeton: Princeton University Press

Williams M. 2014. Introduction — On the use and abuse of recognition in politics. In Recognition versus self-determination-Dilemmas of emancipatory politics, edited by A. Eisenberg, J. Webber, G. Coulthard, and A. Boisselle, 3-20. Toronto: UBC Press. 